\title{
QUANTIFYING SEISMIC RISK FOR PORTABLE GROUND SUPPORT \\ EQUIPMENT AT VANDENBERG AIR FORCE BASE
}

\author{
A Project \\ presented to \\ the Faculty of California Polytechnic State University, \\ San Luis Obispo
}

\author{
In Partial Fulfillment \\ of the Requirements for the Degree \\ Master of Science in Aerospace Engineering
}

by

Joshua Lowe

January 2010 
(C) 2010

Joshua Lowe

ALL RIGHTS RESERVED 


\section{COMMITTEE MEMBERSHIP}

TITLE:

Quantifying Seismic Risk for Portable Ground

Support Equipment at Vandenberg Air Force Base
AUTHOR:
Joshua Lowe
DATE SUBMITTED:
March 2010
COMMITTEE CHAIR:
Dr. Jordi Puig-Suari, Professor
COMMITTEE MEMBER:
Dr. Eric A. Mehiel, Associate Professor / Dept Chair
COMMITTEE MEMBER:
Dr. Robert Crockett, Assistant Professor
COMMITTEE MEMBER: Mark Ware, United Launch Alliance 


\section{ABSTRACT \\ QUANTIFYING SEISMIC RISK FOR PORTABLE GROUND SUPPORT EQUIPMENT AT VANDENBERG AIR FORCE BASE}

Joshua Lowe

This project develops a quantitative method to evaluate the seismic risk for portable GSE at Vandenberg Air Force Base. Using the latest probability data available from the USGS, risk thresholds are defined for portable GSE having the potential to cause a catastrophic event. Additionally, an example tool for design engineers was developed from the seismic codes showing the tipping hazard case can be simplified into strict geometrical terms. The misinterpretation and confusion regarding the Range Safety 24 Hour Rule exemption can be avoided by assessing seismic risk for portable GSE. By using the methods herein to quantify and understand seismic risk, more informed risk decisions can be made by engineering and management. The seismic codes and requirements used and referenced throughout include but are not limited to IBC, ASCE 7, EWR 127-1, and AFSPCMAN 91-710.

Keywords: Seismic, 24 Hour Rule, Vandenberg, Risk 


\section{TABLE OF CONTENTS}

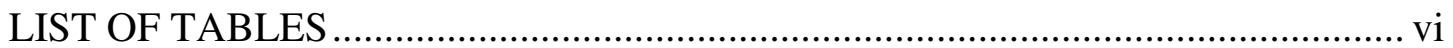

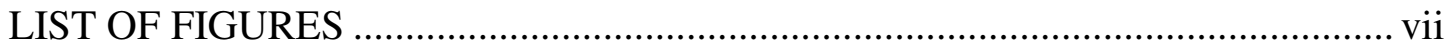

NOMENCLATURE …............................................................................. vii

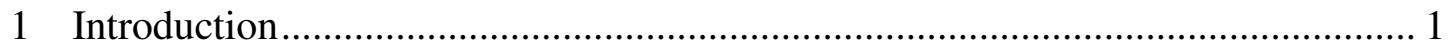

2 Seismic Requirements and Applicability to the Use of Ground Support

Equipment at Vandenberg AFB ....................................................................... 3

2.1 Seismic Requirements........................................................................... 4

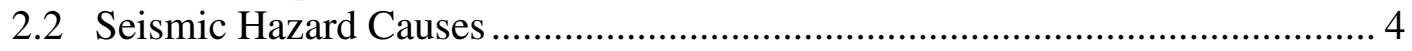

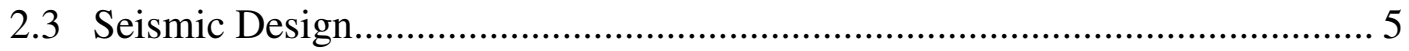

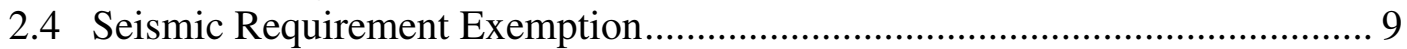

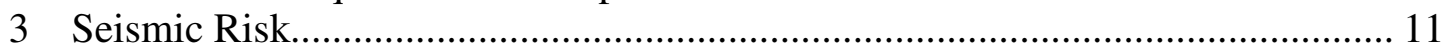

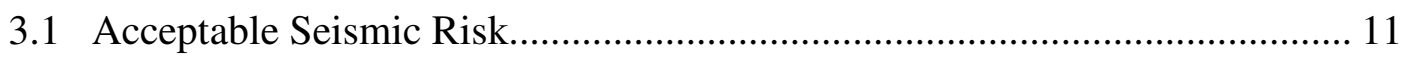

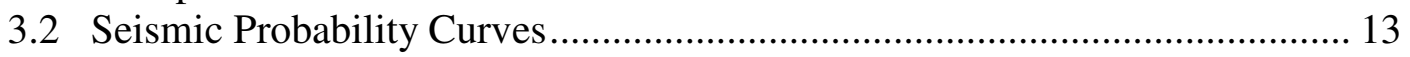

3.3 Seismic Risk Thresholds Defined ............................................................ 15

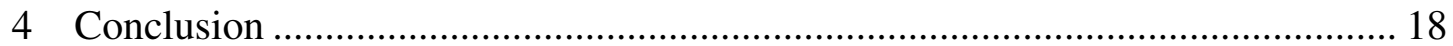

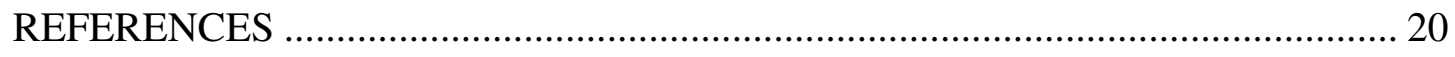

Appendix A. Earthquake Load Calculation ....................................................... 21

Appendix B. Acceptability Guidelines for Prelaunch Launch Area/Launch

Complex Hazard Consequences and Probability Categories ............................... 26

Appendix C. USGS Java Tool Output and Compiled Data .................................... 27 


\section{LIST OF TABLES}

Table C.1. Consolidated USGS Output Data with Calculation Results. .................... 28 


\section{LIST OF FIGURES}

Fig. 1. Generic Free Body Diagram for Portable Ground Support Equipment. .......... 6

Fig. 2. Relationship between Portable Equipment Geometry and Ground Motion...... 8

Fig. 3. USGS Java Tool Screenshot of 0.375g Ground Motion for Zip Code 93437. 13

Fig. 4. Probability of Exceeding Ground Motions per Day at Vandenberg ............... 14

Fig. 5. Risk Threshold Curves for Catastrophic Hazards ......................................... 16 


\section{NOMENCLATURE}

ASCE

AFSPCMAN

b

$\mathrm{cg}$

D

E

EWR

$\mathrm{F}_{\mathrm{a}}$

GSE

$\mathrm{h}$

Hazard

I

IBC

M

ME

SDS

SMS

$\mathrm{S}_{\mathrm{s}}$

USGS
American Society of Civil Engineers

Air Force Space Command Manual

Distance to shortest tip-over axis

Center of gravity

Dead load

Earthquake load (same as V)

Eastern and Western Range

Site Coefficient

Ground Support Equipment

Center of gravity height

Equipment, system, operation, or condition with an

existing or potential condition that may result in injury

to personnel or damage to hardware

Importance factor

International Building Code

Dead moment

Earthquake moment

Design Spectral Acceleration

Maximum Considered Earthquake Spectral Response

Acceleration

Spectral Response Acceleration

US Geological Survey

viii 

a nonbuilding structure (same as E) Nonbuilding structure operating weight 


\section{Introduction}

Based on the author's experience working various launch vehicle and satellite programs at Vandenberg Air Force Base (VAFB), it is evident much confusion exists regarding seismic requirements and their application to portable Ground Support Equipment (GSE). This confusion is partly attributed to the seismic codes, which focus on buildings and permanently installed equipment. Another contributor is the lack of a quantitative method for seismic risk. Risk is defined as the product of hazard severity and probability of occurrence. In an attempt to reduce the probability of occurrence, the Range Safety Regulations ${ }^{1,2}$ allow for an exemption of portable GSE from the seismic requirements if it is used less than 24 hours in a launch cycle or year. The rationale for this exemption lies in the understanding that by reducing the exposure of personnel and property to portable GSE for less than 24 hours per year, the probability of occurrence will be limited thereby reducing the overall risk. In practice this exemption is commonly referred to as the " 24 Hour Rule."

The seismic codes can, at times, be expensive or even cost prohibitive to implement because of resource issues, such as funding or facility constraints. The 24 hour rule was developed for cases limited to 24 hours exposure, and provides full exemption from the seismic requirements. However, this duration is arbitrary and lacking a quantitative approach to risk assessment. It is the goal of this paper to define tools to quantify seismic risk using the latest probability values from the US Geological Survey (USGS) and risk acceptability guidelines from the Range Safety Regulations. This proposed approach will allow companies to better understand and analyze seismic risk at Vandenberg Air Force Base. It is the hope that this improved 
understanding will allow better decisions to be made regarding seismic requirements for portable Ground Support Equipment. 


\section{Seismic Requirements and Applicability to the Use of Ground Support Equipment at Vandenberg AFB}

Companies that use Vandenberg AFB to process satellites and launch vehicles are required to meet the safety requirements as defined by Range Safety Regulations. New launch vehicles or satellites to Vandenberg must meet the safety requirements contained in Air Force Space Command Manual (AFSPCMAN) 91-710. Existing launch vehicles and satellite programs at Vandenberg are likely to fall under the earlier Eastern and Western Range Safety Manual 127-1 (EWR 127-1). Both of these documents contain safety requirements intended to minimize the risk to personnel and equipment during an earthquake. A discussion of requirements applicable to portable GSE is located in Section 2.1.

Risk is the product of hazard severity and the probability of occurrence. The portable GSE used at Vandenberg often handles large and expensive flight hardware. During its use, should a large enough earthquake occur, the potential for catastrophic consequences exists. A catastrophic hazard severity is one that causes death, equipment loss greater than $\$ 500,000$, or unit down time greater than 4 months. ${ }^{1,2}$ Hazard causes are discussed further in Section 2.2.

The probability of occurrence is also required to assess risk. While there is no way of predicting an earthquake, the USGS has developed hazard probability curves which provide probability data based on exceeding a specified ground motion. This is discussed in more detail in Section 3.2. 


\subsection{Seismic Requirements}

AFSPCMAN 91-710, lists International Building Code and ASCE 7 as the basis for equipment design and seismic load combinations in Volume 3 paragraph 17.2. It should be noted that ASCE 7-05, "Minimum Design Loads for Buildings and Other Structures" is referenced throughout 2006 International Building Code (IBC 2006) in

the portable GSE section. ${ }^{3,4}$ It is clear that both IBC and ASCE 7 are the latest seismic codes and must be used when defining seismic requirements and load combinations.

The seismic design section of EWR 127-1 paragraph 3.17.1 lists AFM 88-3

Chapter 13, SEAOC "Blue Book", UBC, and ATC 3-06 as requirements. Of the references listed, very little direction is given regarding portable GSE. Additionally, many of these references in EWR 127-1 have not been recently updated. It is therefore recommended that launch vehicle and satellite programs under EWR 127-1 follow the seismic codes listed in AFSPCMAN 91-710, namely IBC 2006 and ASCE 7-05.

For portable GSE design requirements, the appropriate reference is Chapter 15 of ASCE 7-05. This chapter contains the nonbuilding structure seismic design requirements including the equations to define the earthquake load. Refer to Section 2.3 for further discussion.

\subsection{Seismic Hazard Causes}

During a seismic event, portable GSE is subject to tip-over, sliding, and material collapse. In many cases these motions have the potential to directly or indirectly propagate a catastrophic event involving personnel or flight hardware. Remember that hazard severity is only one part of defining risk. The probabilities of these events occurring are defined in Section 3.2. 
Two of the three hazard causes can be quantitatively assessed, namely tip-over and material collapse. A lateral load as defined by the seismic $\operatorname{code}^{3}$ is applied to the portable GSE using the static equivalent force method (see Section 2.3). This simple quantitative approach avoids the complications of a dynamic model by using conservative assumptions and factors of safety.

Sliding is the hazard cause in which there is no established analytical methods to assess portable GSE in a seismic event. Movement of portable GSE during a seismic event is difficult to bound and an opportunity for further study. Should further study occur, one of the goals should be to define a minimum clear area around portable equipment for sliding hazards. This clear area, the free space around the equipment, would likely be a function of equipment geometry and the magnitude of the seismic event.

\subsection{Seismic Design}

The seismic codes reduce complexity of the dynamic nature of an earthquake by applying loads statically. This is called the static equivalent force method. ${ }^{3}$ Use of this method along with factors of safety allow the engineer to perform a simplified analysis of the loads during a seismic event.

During the design process, portable GSE should be assessed for its ability to resist lateral load for material collapse and tip-over. IBC 2006 and ASCE 7-05 define the

seismic requirements for both portable GSE and restrain design. ${ }^{3,4}$ The incorporation of seismic code requirements into the design will reduce the risk of a catastrophic consequence during an event. 
ASCE 7 has a series of requirements and equations to define the earthquake load. To select the appropriate equations in ASCE 7, the fundamental period, seismic event type, soil composition, and building classifications must be known. An example of the earthquake load calculation along with assumptions is shown in Appendix A.

Once the earthquake load is defined, the appropriate load combinations must be used. Both IBC and ASCE 7 define the load combinations. For most portable GSE, the earthquake load will be applied in a lateral direction through the center of gravity as shown in Fig. 1. This figure shows a piece of portable GSE that is about to tip.

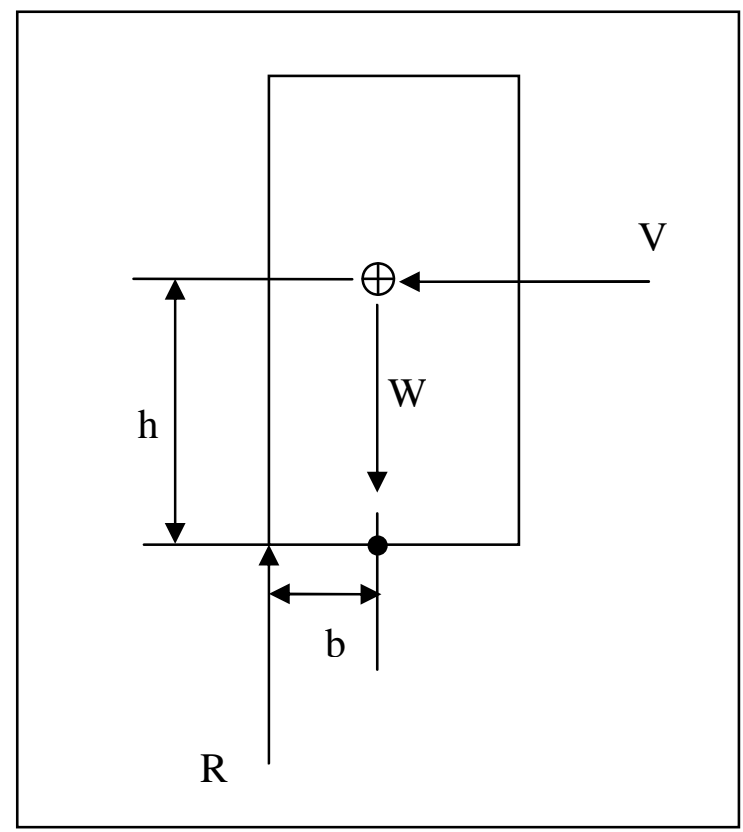

Fig. 1. Generic Free Body Diagram for Tipping Portable GSE.

V - Earthquake Load

W - Weight

$h$ - Center of gravity height

b - Shortest distance to tip-over axis

R - Restoring Force

By using Fig. 1, it can be shown that:

$$
M_{D}=b^{*} R
$$




$$
M_{E}=h^{*} V
$$

$$
R=W
$$

Where $M_{D}$ is the restoring moment and $M_{E}$ is the earthquake moment. Using the load combinations as discussed in Appendix A and applying a 1.5 factor of safety, the equation that must be satisfied becomes:

$$
\frac{0.9 * M_{D}}{M_{E}}>1.5
$$

From the example earthquake load calculation in Appendix A, the result $\mathrm{V}=$ 0.375W, is substituted in Equation 2.4

$$
\begin{aligned}
& \frac{0.9 * b * W}{h * 0.375 * W}>1.5 \\
& \frac{b}{h}>0.63
\end{aligned}
$$

Notice the result in Equation 2.6 is a simple relationship between the geometry of the height equipment center of gravity and the distance to the shortest tip-over axis. Intuitively, having a relationship like this makes sense. Since the relationship was developed using the seismic codes, when inequality is true, no restraints are required for tip-over. Conversely, when inequality is false, a seismic restraint system design or an acceptance of the understood risk is required for the equipment. By having this simple relationship, design engineers have the ability to quickly evaluate portable GSE to seismic codes. However, caution should be used when using this tool. All of the assumptions that went into the calculation must be true for the result to be valid. 
Fig. 2 shows the linear relationship between the ratio of cg height and the distance the shortest base and the lateral load capability. It was developed using the following relationship:

$$
\frac{0.9 * M_{D}}{M_{E}}=1.5
$$

After solving for $\mathrm{b} / \mathrm{h}$ and substituting $\mathrm{x} * \mathrm{~W}$ for $\mathrm{V}$, the result is:

$$
\frac{b}{h}=\frac{15}{9} x
$$

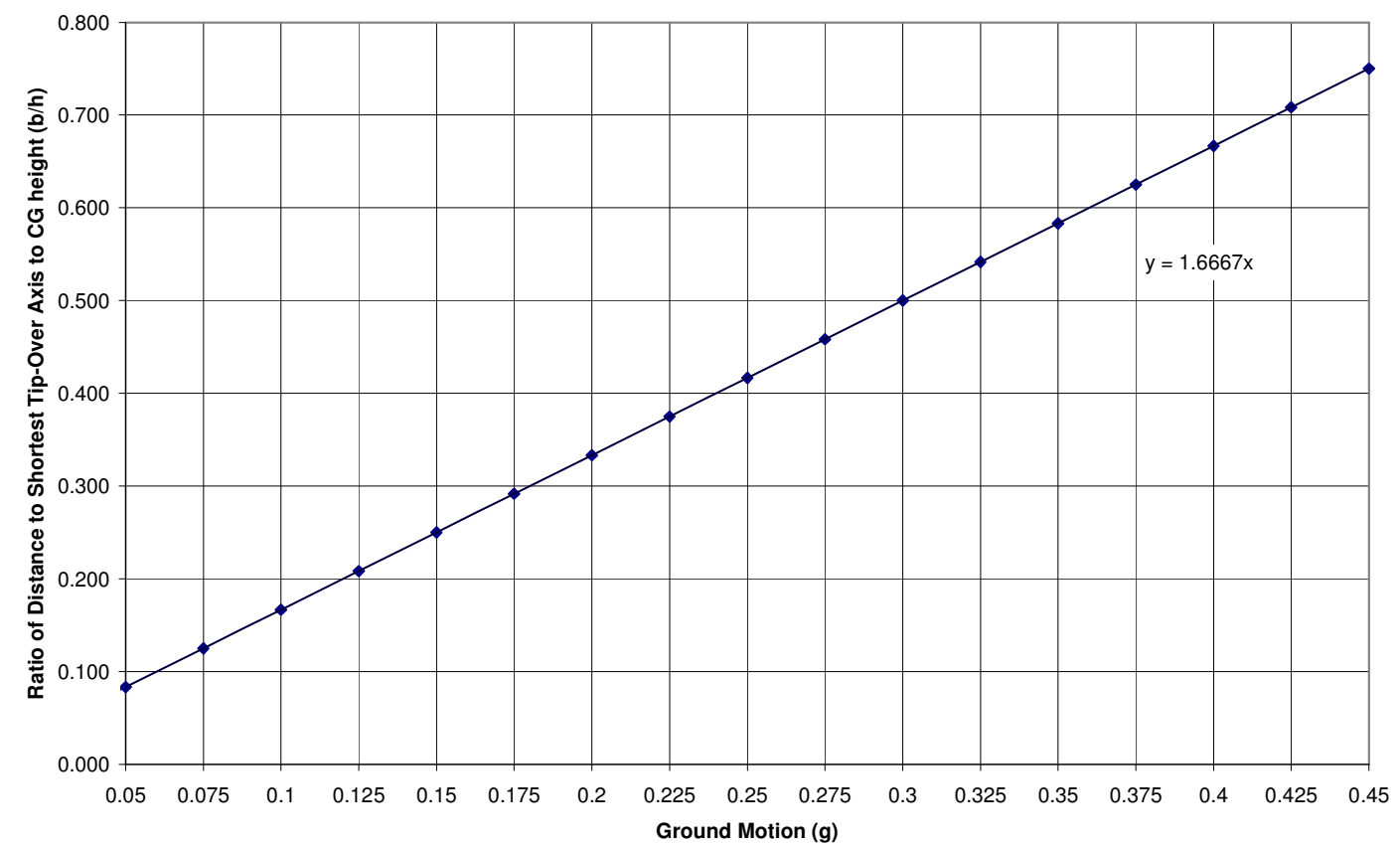

Fig. 2. Relationship between Portable Equipment Geometry and Ground Motion.

In cases where the portable GSE cannot be designed to meet the strength and tipover from the earthquake load, the design engineer would be required to design seismic restraints. These restraints must be designed to adequately resist the lateral load, in accordance with IBC and ASCE 7, and must have appropriate connection points to the GSE and facility being used. 


\subsection{Seismic Requirement Exemption}

Both EWR 127-1 and AFSPCMAN 91-710 list a seismic requirement exemption which eliminates design and restraint requirements based on 24 hours. The "24 Hour Rule" in AFSPCMAN 91-710 paragraph 17.2.5.4 states:

GSE temporarily positioned in support of operations, used in accordance with the 30 SW " 24 hour" rule (in other words, equipment that is used for less than 24 hours per launch cycle), is exempted from seismic design and restraint requirements. ${ }^{1}$

The "24 Hour Rule" in EWR 127-1, paragraph 3.17.2.d states:

Items of equipment that present seismic hazards for a cumulative total of 24 hours or less during any 365 consecutive day cycle are exempt from the above requirements. $^{2}$

The "24 Hour Rule" exemption has been in place for many years and the origin is not exactly known. The author has searched extensively for engineering rationale regarding this exemption and conducted multiple interviews with Vandenberg Range Safety experts. These efforts have provided that the rule was adopted based on a white paper from a contractor risk assessment, which could not be located. A risk assessment will be performed in Section 3 to provide quantitative results based on established risk criteria already present in Range Safety Regulations.

Based on the author's experience working various launch vehicle and satellite programs at Vandenberg, this exemption is often interpreted to provide the greatest schedule benefit to the program while ignoring the risk assessment on which it was originally based. For example, one might interpret the rule that by moving portable equipment from place to place as long as the equipment is not stationary for more than 24 hours, the clock resets once it is moved and the equipment is exempt for 
another 24 hours. This abuse of the exemption increases the risk for injury to personnel and damage to flight hardware without adequately assessing the risk.

There are further exemptions from seismic requirements listed in AFSPCMAN 91710 , as listed in paragraphs 17.5.2.1, 17.2.5.2, and 17.2.5.3. The types of items listed are in general small items, where seismic design or restraint would provide little or no reduction to overall risk.

AFSPCMAN 91-710 lists another requirement under the seismic exemption in paragraph 17.2.5.5, which states:

On a case-by-case basis, those items that may be ruled exempt by Range Safety based on the results of a risk analysis. ${ }^{1}$

Section 3 discusses risk, acceptable risk on Vandenberg, and probability data from the USGS can be used to define risk for portable GSE. 


\section{Seismic Risk}

Risk is made up of two parts, probability and severity. Hazards which produce catastrophic consequences may be considered acceptable risk if the probability of occurrence is low enough. For the purposes of this paper and to allow for the most conservative approach, it is assumed throughout the following sections that any seismic event which exceeds the capability of portable GSE will result in a catastrophic hazard. The focus will be on calculating the probability that a seismic event will occur to quantify the risk.

\subsection{Acceptable Seismic Risk}

Acceptable risk is defined for Range Users in of AFSPCMAN 91-710 Volume 1

Figure 3.2 and the 1997 version of EWR 127-1 Chapter 1 Table 1-1., 2 This table is shown in Appendix B. Using these acceptability guidelines, acceptable risk is defined for catastrophic hazard consequences by probabilities less than 8E-05. For event probabilities between $8 \mathrm{E}-05$ and $8 \mathrm{E}-04$, the risk can be accepted by a deviation or a waiver from Range Safety and program management. Any events which have a probability greater than 8E-04 for catastrophic consequences are defined as unacceptable risk and must be mitigated.

It is assumed that when portable equipment meets the lateral load requirements for tip-over and material collapse, in most cases it is acceptable risk to use this equipment without restraint. However, when this portable equipment is used in facilities where space is limited or hazardous commodities are present, seismic restraints may be required to obtain acceptable risk. 
At Vandenberg, there are many unique portable equipment designs which handle high value flight hardware. Sometimes it is not feasible to design this equipment to meet the seismic codes or implement seismic restraints within a processing flow. The Range Safety Regulations attempt to address this by the " 24 Hour Rule" exemption discussed in Section 2.4. Later in this paper, it will be shown that this exemption is conservative and the quantitative risked based approach presented herein is a more accurate solution.

It should be noted that Paragraph 3.3.2 in AFSPCMAN 91-710 Volume 1 states, "Numbers provided in Figure 3.2. are guides only and are not necessarily hard limits." This must be kept in mind when considering critical national assets where even a very small probability for a catastrophic failure cannot be accepted. For these cases, it is up to the specific program to determine acceptable risk levels. It is not the intention of this paper to address these special cases.

When portable equipment does not meet the lateral load requirements, acceptable risk can be obtained by one of two ways. The first is to design and implement a restraint system to withstand lateral loads. Anchorage design is defined within the seismic codes. ${ }^{3,4}$ The other method to obtain acceptable risk values is to limit the time the equipment is used. It is shown in Section 3.3 that the amount of time which results in acceptable risk is based on the portable GSE lateral load capability and the probability of a seismic event. As defined previously in Section 2.3, the lateral load capability is defined by equipment geometry. The next section, Section 3.2, goes through the method of calculating the probability of a seismic event by using the most current probability data from the USGS. 


\subsection{Seismic Probability Curves}

Probabilities of a seismic event exceeding user defined ground accelerations are available from the US Geological Survey (USGS). A free Java tool, NSHMP_HazardApp.jar, is available for download from the USGS website. ${ }^{5}$ The Java Application includes the latest probabilistic hazard curves available, the 2002 Probabilistic Hazard Curves.

To obtain probability data, the user inputs the location of interest by latitude/longitude or zip code and the ground acceleration into the Java tool. The output is the probability of exceedance per year, the return period, and the probability of exceedance for an exposure time of 50 years. To provide an example, Fig. 3.

USGS Java Tool Screenshot shows a screenshot of the Java tool with Vandenberg zip code 93437 and $0.375 \mathrm{~g}$ ground motion.

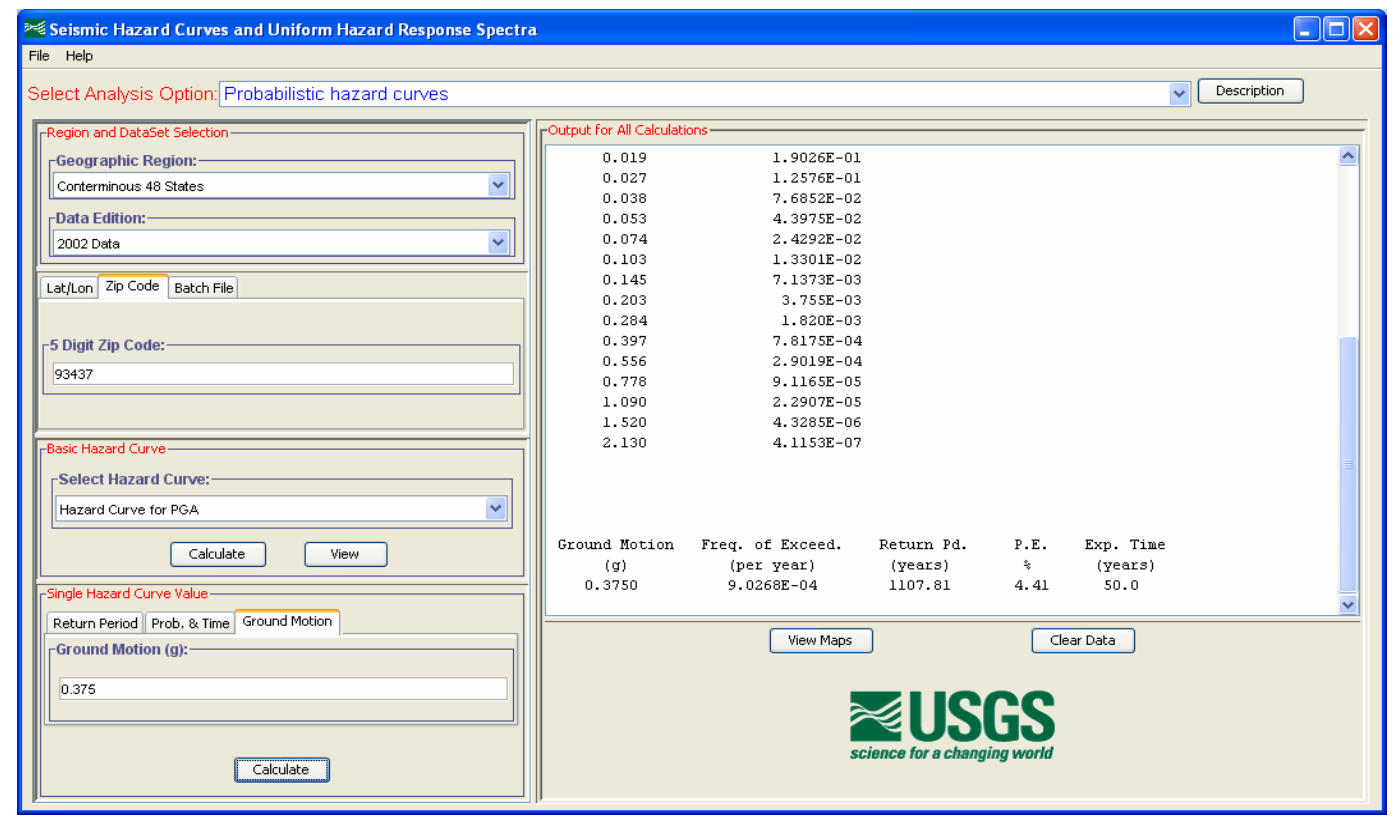

Fig. 3. USGS Java Tool Screenshot of 0.375g Ground Motion for Zip Code 93437 
A set of frequency of exceedance probability values was obtained for Vandenberg ground accelerations from $0.05 \mathrm{~g}$ to $0.375 \mathrm{~g}$ in increments of $0.025 \mathrm{~g}$. The probability values were divided by 365 to obtain the probability of exceedance per day. A graphical representation of the data is shown in Fig. 4. The tabular data is available in Appendix C. Breaking down the probabilities per day allows the development of risk curves in Section 3.3.

Probability of Exceeding Accelerations in Zip Code 93437 based on 2002 Probablistic Hazard Curves from USGS

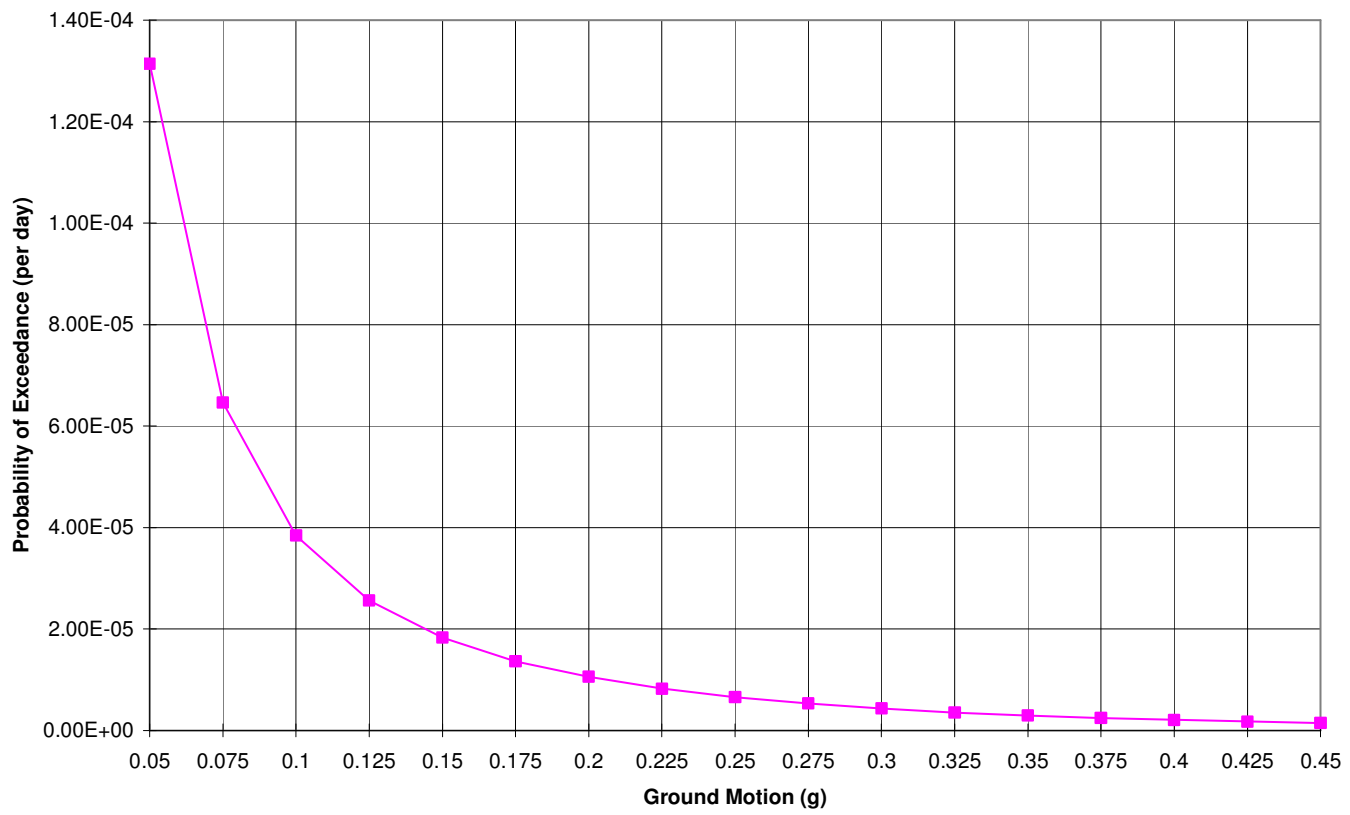

Fig. 4. Probability of Exceeding Ground Motions per Day at Vandenberg

One of the cautions listed in the Java tool output is for Frequency of Exceedance values less than 1E-04. For ground motions of $0.45 \mathrm{~g}$, the Frequency of Exceedance for a year is $5.4 \mathrm{E}-04$, which is greater than $1 \mathrm{E}-04$. 


\subsection{Seismic Risk Thresholds Defined}

The data contained in Fig. 4 can be used to calculate risk curves based on the Acceptability Guidelines defined by Range Safety Regulations (see Appendix B). To calculate the risk curves, divide the threshold values by the daily probability of exceedance. For catastrophic failures, the threshold values between Extremely Improbable and Remote (8E-05) and Remote and Occasional (8E-04) categories were of interest. The results are graphically represented in Fig. 5. It should be noted that acceptable and unacceptable risk are shown on the chart, as well as an additional category in the middle. For the region between acceptable and unacceptable risk, the risk can be accepted given the proper authority signs the requirement waiver or deviation as defined by the Range Safety Regulations. ${ }^{1,2}$ Without a signed requirement deviation or waiver, the risk is unacceptable and must be mitigated. Data tables of which the figure is based can be found in Appendix C. 


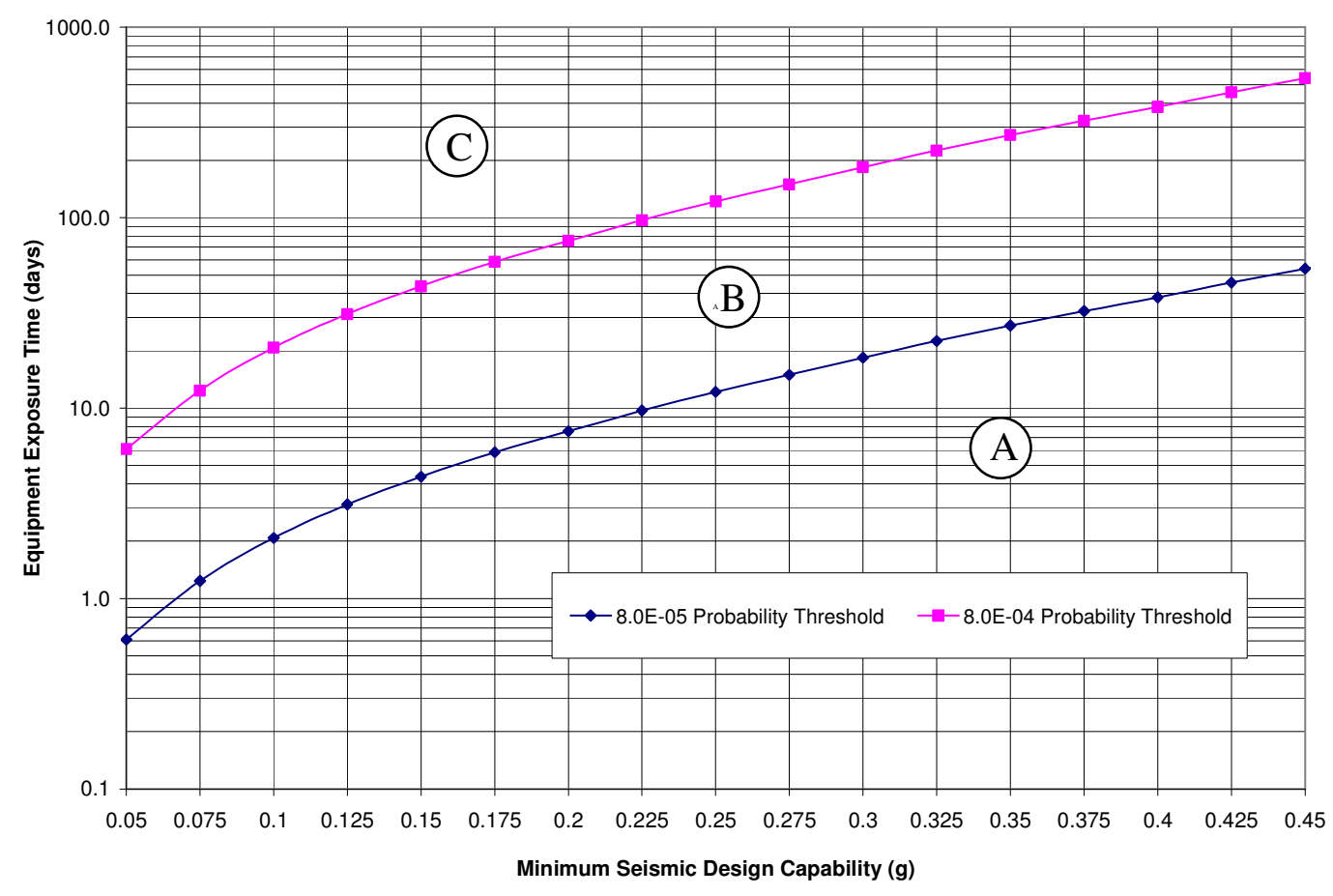

Fig. 5. Risk Threshold Curves for Catastrophic Hazards A - Acceptable Risk B - Risk Acceptable with an Approved Requirement Waiver or Deviation C - Unacceptable Risk

The information contained in the risk threshold curves of Fig. 5 has the potential to profoundly change the way seismic risk for portable equipment is assessed. For example, assume there is portable GSE that does not meet the seismic codes for tipover or collapse. After a structural and tip-over evaluation, it is determined that this hypothetical portable GSE can withstand a minimum of $0.225 \mathrm{~g}$ lateral load.

According to the threshold curves in Fig. 5, it is acceptable risk to use this equipment in this configuration if the duration of the activity is less than 10 days. Should the duration of the activity be greater than 10 but less than 100 days, a requirement deviation or waiver must be obtained to accept the risk. For activities exceeding 100 days in duration, the risk is unacceptable and the equipment either needs to be 
redesigned, seismically restrained, or the exposure time needs to be reduced below 100 days.

Fig. 5 shows that portable GSE, depending on design, can be used with acceptable risk for durations exceeding 24 hours. However, the key to using this starts with an understanding of the equipment capability. This seismic assessment must at minimum show GSE design capabilities for material collapse and tip-over and discuss the nominal duration of the process flow. It is worth noting again (see Section 2.3), if the equipment does not meet the seismic codes, it is due diligence to design a seismic restraint system. Consequently, if the planned timelines exceed the threshold limit, the opportunity to install restraints is available.

It should be noted again that Fig. 5 is based off of 2002 Hazard Curves from the USGS. When new data is available from USGS, these curves can be recalculated based on the latest available data. 


\section{Conclusion}

Seismic design requirements for portable GSE used at Vandenberg AFB is complicated and misunderstood. At the center of this confusion is the 24 Hour Rule, which exempts the portable equipment from all of the seismic requirements if it is used for less than 24 hours. Originally this exemption was based on a risk assessment; however applying this exemption to all GSE is arbitrary. It has been shown that seismic risk, the consequence of a seismic hazard and probability of its occurrence, can be quantitatively defined using the latest available probability curves from the USGS and the risk thresholds defined by the Range Safety Regulations. Using the GSE design capability for both tip-over and collapse, acceptable risk duration can be calculated for equipment that has the potential to cause a catastrophic hazard.

An interesting geometric result was obtained when defining the Free Body Diagram for an almost tipping generic piece of portable equipment. When substituting the earthquake load calculated from ASCE 7, it was shown that the code was simplified to a relationship between the center of gravity height and the distance to the shortest base. This relationship has the potential to be a very useful tool to design engineers as a quick calculation can determine whether the portable GSE in question meets the seismic codes. It was noted that this relationship must be used cautiously; all of the assumptions that went into the earthquake load calculation must be true.

The risk assessment tools defined herein will help design engineering implement seismic requirements for portable GSE. These tools can also help managers 
understand seismic risk and make better risk based decisions. Finally, it is the hope that this quantitative process will clear up the confusion regarding the seismic requirements and help save companies time and money in the process. 


\section{REFERENCES}

1. Air Force Space Command Manual (AFSPCMAN) 91-710, 1 July 2004.

2. Eastern and Western Range Safety Manual (EWR) 127-1, 31 October 1997.

3. ASCE/SEI, "Minimum Design Loads for Buildings and Other Structures," American Society of Civil Engineers, 2005. ASCE 7-05.

4. International Code Council (ICC), "International Building Code", 2006. IBC 2006.

5. Earthquake Ground Motion Parameters. Computer software. Version 5.0.9a. Download. Java Tool, October 21, 2009. Seismic Hazard Curves and Uniform Hazard Response Spectra.

http://earthquake.usgs.gov/hazards/design/buildings.php. 


\section{Appendix A. Earthquake Load Calculation}

The intent of this appendix is to provide a logical discussion for defining the earthquake load using the latest seismic codes. IBC 2006 Section 1613, "Earthquake Loads" states the following:

Every structure, and portion thereof, including nonstructural components that are permanently attached to structures and their supports and attachments, shall be designed and constructed to resist the effects of earthquake motions in accordance with ASCE 7... The seismic design category for a structure is permitted to be determined in accordance with Section 1613 or ASCE 7.

The latest version of ASCE 7 was made in 2005. Chapter 15 within ASCE 7-05 contains the seismic design requirements for nonbuilding structures. This chapter is the best fit for portable Ground Support Equipment at Vandenberg. ASCE 7-05 will be used throughout this appendix to provide an example earthquake load calculation.

Many conservative assumptions go into this example earthquake load calculation. It is assumed that the portable GSE and the attached hardware make up a rigid system. Additionally it is assumed that short period seismic event occurs, yielding the highest earthquake load. The soil type is unknown and depends specifically on the site location; therefore Site Classification D is assumed per ASCE 7. Assuming Site Classification D is conservative most regions. Lastly Occupancy Category IV is assumed and provides the highest and most conservative importance factor.

Portable GSE in most cases is not similar to buildings and therefore must meet Section 15.3 and Table 15.4-2. The subparagraphs of Section 15.3 make further requirement distinctions based on the weight the portable GSE and the weight of the hardware it is handling. For portable GSE that has rigid characteristics, paragraph 
15.3.2.1 applies, whereas non-rigid requirements are defined in paragraph 15.3.2.2.

Table 15.4-2 defines the seismic coefficients for nonbuilding structures not similar to buildings.

The lateral force for rigid structures is defined in paragraph 15.4.2. This force will be used to define the earthquake load. It defines rigid as structures with a fundamental period less than 0.06 seconds. When this is true, the following lateral force equation shall be used:

$$
V=0.30 S_{D S} W I
$$

where

$\mathrm{V}=$ the total design lateral seismic base shear force applied to a nonbuilding structure

$S_{D S}=$ the site design response acceleration as determined from Section 11.4.4

$\mathrm{W}=$ nonbuilding structure operating weight

$\mathrm{I}=$ the importance factor determined in accordance with Section 15.4.1.1

First determine $S_{D S}$ using Section 11.4.4. This section defines the design spectral acceleration parameters. Assuming short period, the following equation should be used:

$$
S_{D S}=\frac{2}{3} S_{M S}
$$

The Maximum Considered Earthquake (MCE) spectral response acceleration for short periods, $S_{M S}$, is defined in Section 11.4.3. The equation is given as:

$$
S_{M S}=F_{a} S_{S}
$$

(ASCE 7-05, Eqn. 11.4-1) 
where

$F_{a}=$ Site Coefficient

$S_{s}=$ the mapped MCE spectral response acceleration at short periods as determined in accordance with Section 11.4.1

Section 11.4.1 references figures in Chapter 22 to determine $S_{s}$. Figure 22-3, "Maximum Considered Earthquake Ground Motion for Region 1 of 0.2 sec spectral Response Acceleration (5\% critical damping), site Class B," for Vandenberg returns the following value for MCE spectral response acceleration:

$$
\mathrm{S}_{\mathrm{s}}=1.25
$$

Once $S_{s}$ has been determined, the site coefficient $F_{a}$ can be selected using Table 11.4-1. Assuming Site Class D, as instructed in Section 11.4.2 for soil properties that are not well known, the following Site Coefficient was obtained:

$$
F_{a}=1.0
$$

Now that both $S_{s}$ and $F_{a}$ are known, $S_{M S}$ and consequently $S_{D S}$ can be calculated.

The only remaining variable to be determined to calculate lateral load is the importance factor, I.

The importance factor selection criteria are listed in Section 15.4.1.1, one being Table 15.5-1. This table provides importance factors based on the building Occupancy Category. Table 1-1 provides definitions for all Occupancy Categories, I through IV. Depending on the circumstances, it is conceivable that a facility at Vandenberg could be determined as an Occupancy Category III. Should this be the case, Table 15.5-1 would define the importance factor of 1.25. However, for 
conservatism this example will assume Occupancy Category IV, thus defining importance factor that must be used is 1.5 .

All values are now defined to calculate the lateral load V:

$$
\begin{aligned}
& V=0.30 \frac{2}{3}(1.0)(1.25) W(1.5) \\
& V=0.375 W
\end{aligned}
$$

It has yet to be determined how this lateral load will be distributed. Section 15.4.3 references Section 12.8.3 to determine the distribution of the load. It should be noted that Section 12.8 defines the Equivalent Lateral Force Procedure. Using the equations in Section 12.8.3, it can be shown that the lateral load distribution for a rigid structure can be distributed at one point on the structure. When calculating tipping, a conservative approach is taken and the lateral load is applied at the center of gravity.

The load combinations are defined in IBC 2006.

$$
\begin{aligned}
& 1.2 D+f_{1} L+E_{m} \\
& 0.9 D+E_{m}
\end{aligned}
$$
(IBC 2006, Eqn. 16-23)

Where:

$\mathrm{D}=$ Dead load

$\mathrm{E}_{\mathrm{m}}=$ the maximum effect of horizontal and vertical forces as set forth in Section

\subsection{3 of ASCE 7}

$\mathrm{f}_{1}=1$ for floors in places of public assembly, for live loads in excess of $100 \mathrm{psf}$, and for parking garage live load

$$
=0.5
$$

L = Live load 
Portable GSE typically does not have a live load, therefore $\mathrm{L}=0$. It can be seen that IBC 2006 Equation 16-23 is more restrictive and shall be used for tip-over calculations. 


\section{Appendix B. Acceptability Guidelines for Prelaunch Launch Area/Launch Complex Hazard Consequences and Probability Categories}

\section{Acceptability Guidelines for Prelaunch Launch Area/Launch Complex Hazard Consequences and Probability Categories}

\begin{tabular}{|c|c|c|c|c|c|c|c|c|c|}
\hline HAZARD SEVERITY & \multicolumn{4}{|c|}{ POTENTIAL CONSEQUENCES } & \multicolumn{5}{|c|}{ PROBABILITY* } \\
\hline Category & $\begin{array}{c}\text { Personnel } \\
\text { IIIness/Injury }\end{array}$ & $\begin{array}{l}\text { Equipment } \\
\text { Loss(\$) }\end{array}$ & $\begin{array}{c}\text { Unit } \\
\text { Downtime }\end{array}$ & $\begin{array}{c}\text { Data } \\
\text { Compromise }\end{array}$ & $A$ & B & C & $\mathrm{D}$ & $E$ \\
\hline I $\quad$ Catastrophic & May cause death. & $>500,000$ & $>4$ months & $\begin{array}{l}\text { Data is never recoverable or } \\
\text { primary program objectives are } \\
\text { lost. }\end{array}$ & & & & "2. & \\
\hline II $\quad$ Critical & $\begin{array}{l}\text { May cause severe } \\
\text { injury or severe occu- } \\
\text { pational illness. }\end{array}$ & $\begin{array}{c}100,000 \\
\text { to } \\
500,000\end{array}$ & $\begin{array}{l}2 \text { weeks } \\
\text { to } \\
4 \text { months }\end{array}$ & $\begin{array}{l}\text { May cause repeat of test pro- } \\
\text { gram. }\end{array}$ & & & 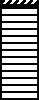 & & \\
\hline III Marginal & $\begin{array}{l}\text { May cause minor } \\
\text { injury, or minor occu- } \\
\text { pational illness. }\end{array}$ & $\begin{array}{c}1000 \\
\text { to } \\
100,000\end{array}$ & $\begin{array}{c}1 \text { Day } \\
\text { to } \\
2 \text { Weeks }\end{array}$ & $\begin{array}{l}\text { May cause repeat of test pe- } \\
\text { riod. }\end{array}$ & & 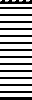 & & & \\
\hline IV Negligible & $\begin{array}{l}\text { Will not result in injury, } \\
\text { or occupational illness. }\end{array}$ & $<1000$ & $<1$ Day & $\begin{array}{l}\text { May cause repeat of data point, } \\
\text { or data may require minor ma- } \\
\text { nipulation or computer rerun. }\end{array}$ & & & & & \\
\hline
\end{tabular}

RISK PRIORITY: $\quad$ UIIIA Unacceptable Waiver or deviation required $\square$ Operation permissible

* Refers to the probability that the potential consequence will occur in the life cycle of the system (test/activity/operation). Use the following list to determine the appropriate Risk Level.

\begin{tabular}{|c|c|c|c|c|c|}
\hline & DESCRIPTION ${ }^{\star \star}$ & $\begin{array}{l}\text { THRESHOLD } \\
\text { LEVEL }\end{array}$ & $\begin{array}{l}\text { PROBABILITY } \\
\text { VALUE }\end{array}$ & SPECIFIC INDIVIDUAL ITEM & FLEET OR INVENTORY*** \\
\hline$A$ & Frequent & $0^{-2}$ & $3 \times 10^{-1}$ & Likely to occur repeatedly & Continuously experienced \\
\hline B & $\begin{array}{l}\text { Reasonably } \\
\text { probable }\end{array}$ & $v=0^{-3}$ & $3 \times 10^{-2}$ & Likely to occur several times & Will occur frequently \\
\hline C & Occasional & $8 \times 10^{-4}$ & $3 \times 10^{-3}$ & Likely to occur sometime & Will occur several times \\
\hline D & Remote & $0 V 10^{-5}$ & $3 \times 10^{-4}$ & Unlikely to occur, but possible & $\begin{array}{l}\text { Unlikely, but can reasonably be } \\
\text { expected to occur }\end{array}$ \\
\hline$E$ & $\begin{array}{l}\text { Extremely } \mathrm{Im}- \\
\text { probable }\end{array}$ & & $3 \times 10^{-5}$ & $\begin{array}{l}\text { The probability of occurrence cannot be } \\
\text { distinguished from zero. }\end{array}$ & Unlikely to occur, but possible \\
\hline
\end{tabular}

** Definitions of descriptive words may have to be modified based on quantity involved.

*** The size of the fleet or inventory and system life cycle should be defined. 


\section{Appendix C. USGS Java Tool Output and Compiled Data}

Output example from USGS Java Tool, using 93437 Zip Code and 0.375g Ground Motion.

Conterminous 48 States

2002 Data

Hazard Curve for PGA

Zip Code - 93437

Zip Code Latitude $=34.749298$

Zip Code Longitude $=-120.5140$

Data are based on a 0.05 deg grid spacing

Frequency of Exceedance values less than

$1 \mathrm{E}-4$ should be used with caution.

$\begin{array}{cc}\begin{array}{c}\text { Ground Motion } \\ (\mathrm{g})\end{array} & \begin{array}{c}\text { Frequency of Exceedance } \\ \text { (per year) }\end{array} \\ 0.005 & 4.4878 \mathrm{E}-01 \\ 0.007 & 3.9773 \mathrm{E}-01 \\ 0.010 & 3.3472 \mathrm{E}-01 \\ 0.014 & 2.6326 \mathrm{E}-01 \\ 0.019 & 1.9026 \mathrm{E}-01 \\ 0.027 & 1.2576 \mathrm{E}-01 \\ 0.038 & 7.6852 \mathrm{E}-02 \\ 0.053 & 4.3975 \mathrm{E}-02 \\ 0.074 & 2.4292 \mathrm{E}-02 \\ 0.103 & 1.3301 \mathrm{E}-02 \\ 0.145 & 7.1373 \mathrm{E}-03 \\ 0.203 & 3.755 \mathrm{E}-03 \\ 0.284 & 1.820 \mathrm{E}-03 \\ 0.397 & 7.8175 \mathrm{E}-04 \\ 0.556 & 2.9019 \mathrm{E}-04 \\ 0.778 & 9.1164 \mathrm{E}-05 \\ 1.090 & 2.2907 \mathrm{E}-05 \\ 1.520 & 4.3284 \mathrm{E}-06 \\ 2.130 & 4.1152 \mathrm{E}-07\end{array}$
Ground Motion $\quad$ Freq. of Exceed. Return Pd. $\quad$ P.E. Exp. Time
(g)
0.3750
(per year)
9.0268E-04
(years) $\%$ (years)
$\begin{array}{lll}1107.82 & 4.41 & 50.0\end{array}$


Table C.1. Consolidated USGS Output Data with Calculation Results.

\begin{tabular}{|c|c|c|c|c|}
\hline $\begin{array}{c}\text { Ground } \\
\text { Motion (g) }\end{array}$ & $\begin{array}{c}\text { Frequency of } \\
\text { Exceedance, } \\
\text { per year }\end{array}$ & $\begin{array}{c}\text { Frequency of } \\
\text { Exceedance, } \\
\text { per day }\end{array}$ & $\begin{array}{c}\text { Number of } \\
\text { Days to 8E-5 } \\
\text { Probability }\end{array}$ & $\begin{array}{c}\text { Number of } \\
\text { Days to 8E-4 } \\
\text { Probability }\end{array}$ \\
\hline 0.050 & $4.80 \mathrm{E}-02$ & $1.35 \mathrm{E}-04$ & 0.6 & 6.1 \\
\hline 0.075 & $2.36 \mathrm{E}-02$ & $6.54 \mathrm{E}-05$ & 1.2 & 12.4 \\
\hline 0.100 & $1.40 \mathrm{E}-02$ & $3.87 \mathrm{E}-05$ & 2.1 & 20.8 \\
\hline 0.125 & $9.35 \mathrm{E}-03$ & $2.57 \mathrm{E}-05$ & 3.1 & 31.2 \\
\hline 0.150 & $6.69 \mathrm{E}-03$ & $1.84 \mathrm{E}-05$ & 4.4 & 43.6 \\
\hline 0.175 & $4.98 \mathrm{E}-03$ & $1.37 \mathrm{E}-05$ & 5.9 & 58.6 \\
\hline 0.200 & $3.86 \mathrm{E}-03$ & $1.06 \mathrm{E}-05$ & 7.6 & 75.6 \\
\hline 0.225 & $3.01 \mathrm{E}-03$ & $8.25 \mathrm{E}-06$ & 9.7 & 97.1 \\
\hline 0.250 & $2.40 \mathrm{E}-03$ & $6.57 \mathrm{E}-06$ & 12.2 & 121.9 \\
\hline 0.275 & $1.95 \mathrm{E}-03$ & $5.35 \mathrm{E}-06$ & 15.0 & 149.7 \\
\hline 0.300 & $1.59 \mathrm{E}-03$ & $4.35 \mathrm{E}-06$ & 18.4 & 184.2 \\
\hline 0.325 & $1.30 \mathrm{E}-03$ & $3.55 \mathrm{E}-06$ & 22.5 & 225.4 \\
\hline 0.350 & $1.07 \mathrm{E}-03$ & $2.94 \mathrm{E}-06$ & 27.2 & 271.8 \\
\hline 0.375 & $9.03 \mathrm{E}-04$ & $2.47 \mathrm{E}-06$ & 32.3 & 323.5 \\
\hline 0.400 & $7.65 \mathrm{E}-04$ & $2.10 \mathrm{E}-06$ & 38.2 & 381.9 \\
\hline 0.425 & $6.40 \mathrm{E}-04$ & $1.75 \mathrm{E}-06$ & 45.6 & 456.4 \\
\hline 0.450 & $5.41 \mathrm{E}-04$ & $1.48 \mathrm{E}-06$ & 54.0 & 540.0 \\
\hline
\end{tabular}

